LA-6291-MS

Informal Report

UC-28

Reporting Date: March Issued: April 1976

\title{
Thermal Stress Analysis of Tungsten Collimators Heated by High-Energy Proton Beams
}

by

Robert W. Meier

Kenneth H. Duerre

of the University of Californio

LOS ALAMOS, NEW MEXICO 87545

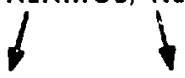

An Affirmotive Action / Equal Opporlunity Employer 
This work was supported by the US Energy Rexiaril and Development Administration. Division of Physical Research.

Printed in the United States of America. Available from National Technical Information Service U.S. Department of Coinmerce 5285 Port Royal Road Springfield, VA $2215 i$

Price: Printed Copy \$3.50 Microfiche \$2.25

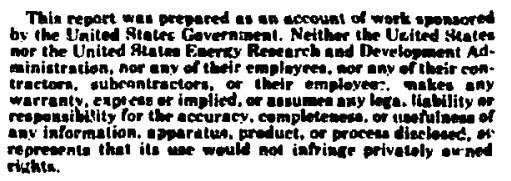

repithe. 


\section{THEBAL STRESS waLYSIS of TUASTEN COLLIMTOAS}

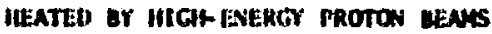

by

Robert W. Meiter and kenneth II. therre

\section{ABSTaAT}

An andiftical and nuerical investigution of the effect of - Iarge quancicy of hith-enery protons on a cungsten alloy colliencor is undertaken herein. Three different ades of faliture are analyzed: thormal stress, therml shock, and cemparature in excess of the manimu allowable.

Three analyses nre developed to study the first bew pulse at I-at buaf current. A qunst-steady-state andygis is appl led co study the offect of aitiple bean pulses at 0 . I- ma ben current.

The results for a I-ah ben indicete that the yleid stress is exceeded afte: 200 us, but the ultinute stress is not rasched during the first bean pulse. The unalytical solution is found co stve cood results in the elestie range. The murrical solution for 0.1-an bean current whows thet the yteld stress is reached after $0.23 \times$ and the ultimate stress is exceeded after 0.48 .

\section{INTROHKTTION}

This study was indertaken to invextigate the interaction of high energy proron beass with colli. antors. The Cinton $\mathrm{b}$. Anderson Meson Jhysics Facility is a proton linear atcelerakar which is capable of acceletating protons to enerafes up to 000 weV at an average curtent of $1 \mathrm{~m}$.

Ideally. the bean moves directly down the center of the annular-shaped collimiors and strikes the target. At times. however, the bean any stray off target and deposti lis chergy into a colfinator. The energy deposited into a colliastor when a terge quantity of protons strike the collimitor causes thermal seresses to dovelop. The purnose of this study was to investigate the effert of deposition of highly consentrated bean cherky itito a colliwstor.

Several possible fallure modes exist. One posstble wode of fallure is that she maximat allowable temerature of the material will he exceded. Another possibilizy is that localized heacing of the collinater wbll establt th therwil thessex exced the yield or ultisute stress af the wate A third posstble wode of failure is thet stoct. wight bo generoted in the eterial by tho pulis noture of the beas cherzy depostion.

Actention was focused on the first collitu in the bene line which is destingted colltmitor The collinator is mehined from a tungsten cliso) composed of $954 \%, 3.54 \mathrm{~N}$. and 1.54 Fo. The 8 etry of the collimstor is shown in fig. 1 .
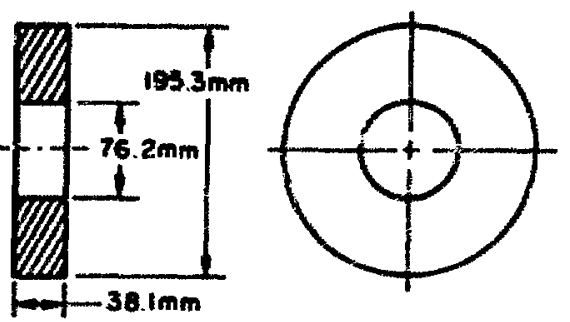

fig. I. Collimator A-l. 
The beature curretio, and thorefore the power de.

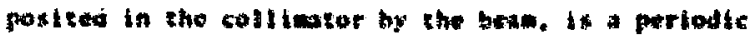

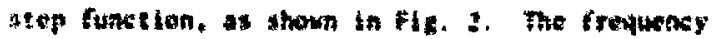

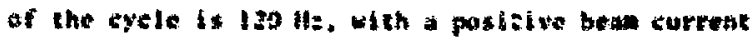

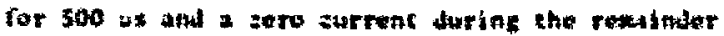
of the sycte.

Tho upatiol distritution of botw current in $\Rightarrow$

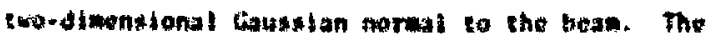
chereat Jentey is dowcribes by

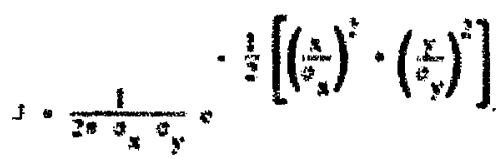

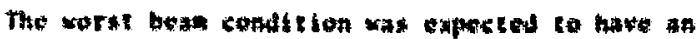
averate current of 1 math an asper rallo of 10 . for wich the seandard davingions of the curreat

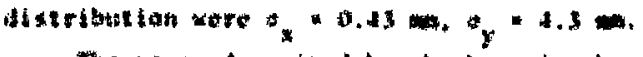

The power depostred by the boum ta the calli.

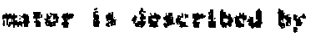

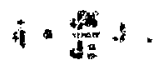

it cuncken.

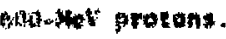

A5 the prowen bas cheth the sallimater the

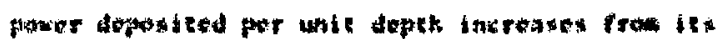

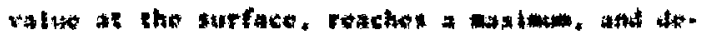

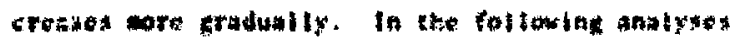

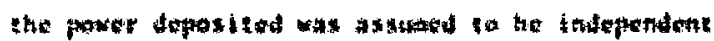

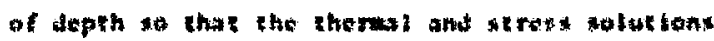

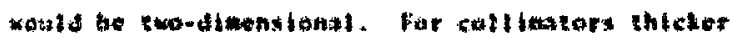

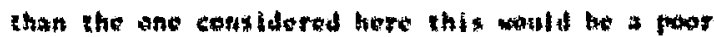

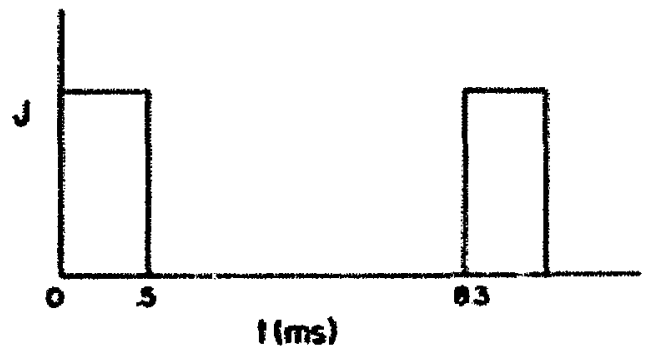

Hif. 2. Heas current as a function of tome.

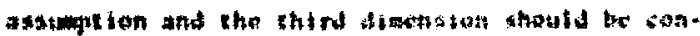
stuered.

\section{Matrfteat wotigton}

An analyelial solutian was abeatiod fot the

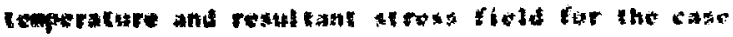

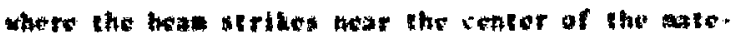

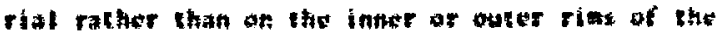

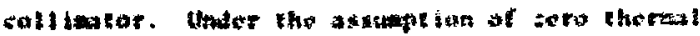

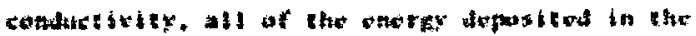

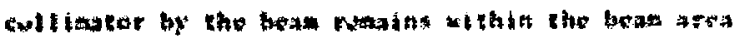
and is nieto by

a $+4=0$

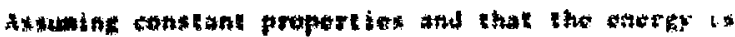

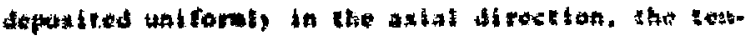

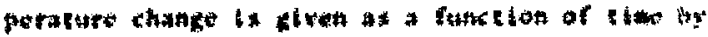

;1)

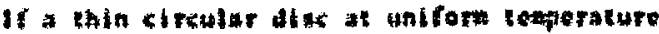

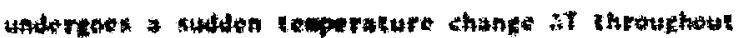

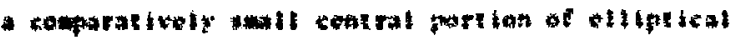

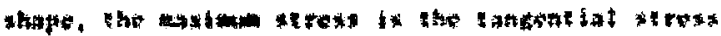
at the ent of the ollipue,

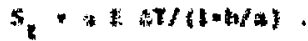

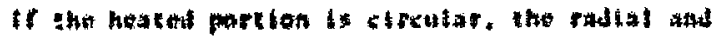

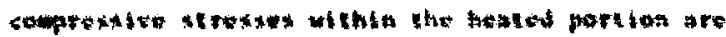
artat

$+.5+\frac{1}{4}+4$.

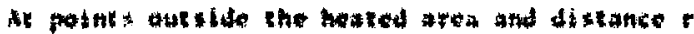

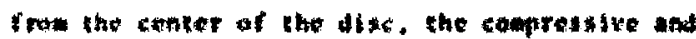

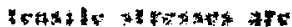

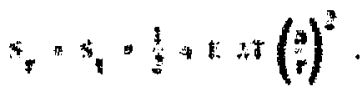

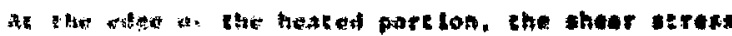
is itten iny 
$S_{\text {iss }}=\frac{1}{3} \times 1: 4$.

The klate of stcess in the paterial is indicated in Fif. 3. The stross secreases rapidiy with distance frow the heated area. At a distahce of one radius awy frow the heoted ares. the stress is at ready re. suted to and-ninth its matimet.

Stbstitution of kq. (4) into $\mathrm{kq}$. (5) ylelds a relation for the maximum tankential stress at the ends of at ellipelcally shapued beam as a function of tistor.

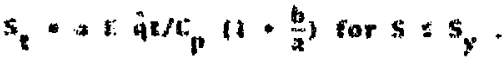

Lquation (1) anglios wht it the yeld stress is

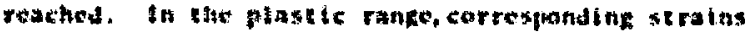
pradtace rolatitaly hawer serokes. In this ranke,

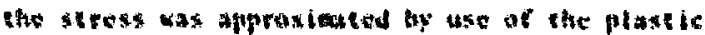

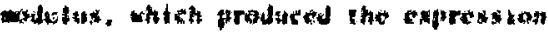

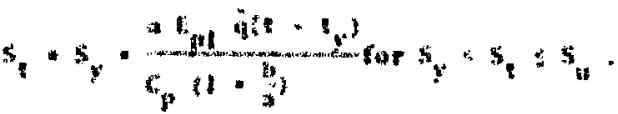

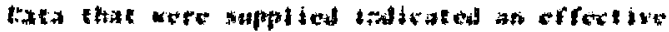

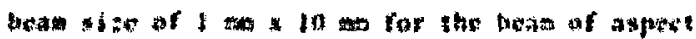

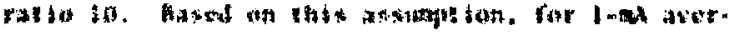

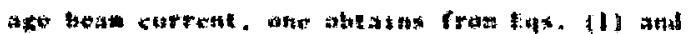

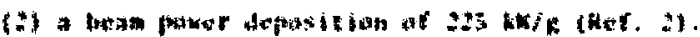

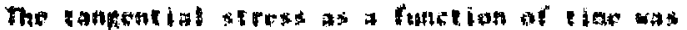

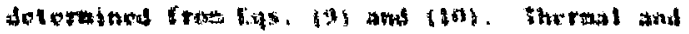

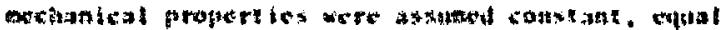

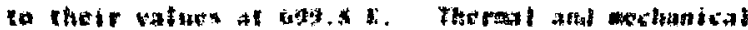

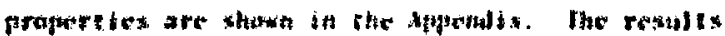

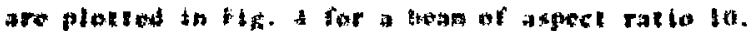

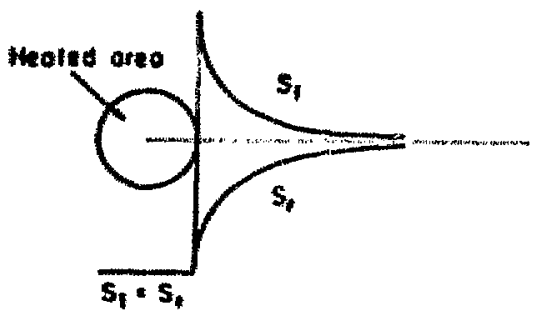

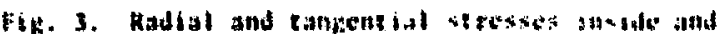
in the vicintey of $a$ salt ifoulior aron whted is retuldenty hested.

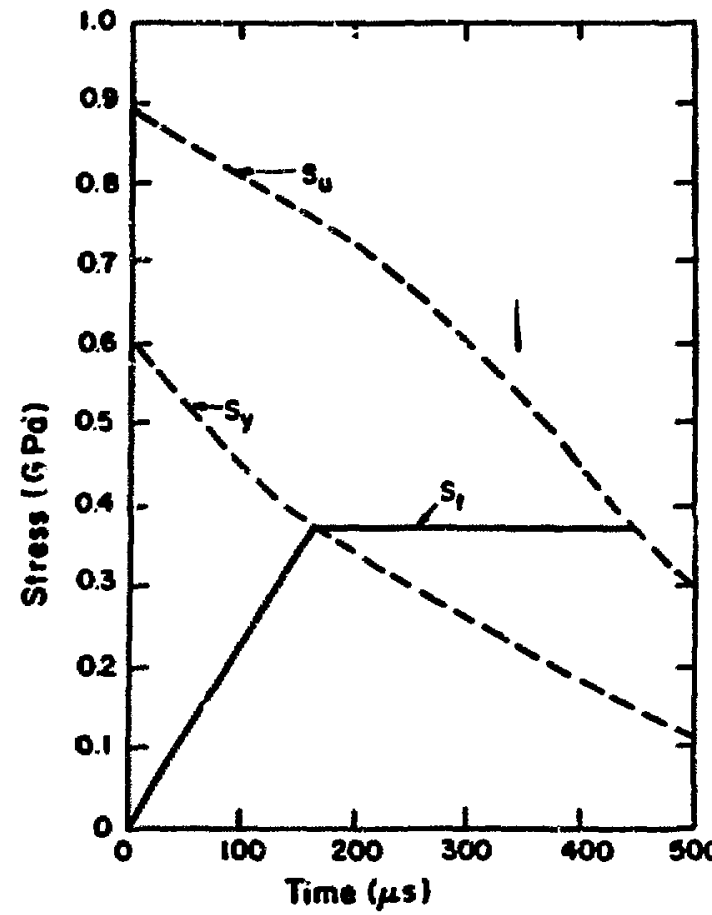

Fig. A. Anstytical solution for mateu cangentia seress for an elliprical bean of aspect rat bo 10 .

The yield and witiate censile stresses were sunertaposed on the compressive stress results by alculating the temperature within the bean arca a a function of tiese from En. (4). The yield and te stle strotses at a piven time were then deternined frow the cemperature-dependent propertios des in the Appendta, assuming an intizil ix eperature of IIn. $\mathrm{n}$.

the aralytical results indlcate that yielding of the colliator w11 occur after $165 \mathrm{~ms}$ and the ultinate tensile stress will the reached afrer 445

\section{ItI. Nuniktcal. solutrion}

Nimerical solutions to the collinator heat ins problew were oblained by ase of $i$ we therenl and st ress analysis code TSAas. 3 mas is a finitc clo actit cole capabic of solving transicnt probleas unc axisymeotric thermal and mechanical loads. A. Itesh

After experimenting with several different nod potite weshes, a wesh was chosen which achicued a fi enough discretization to ohtain significant results 
in the vicinity of the beam and still stay within the maximum number of nodal points allowed by the code, which is 1600 . If the beain contacts the collimatur in the vertiral or horizontal directions. the problem is symetrical and only half of the collimator need be considered. Also, since conduction was anticipated to be of relatively minor importance for time scales of the order of several beam pulses. it was anticipated that the stresses would be concentrated in the vicinity of the beam. Therefore, a $30^{\circ}$ annular segaent, as shown in Fig. 5 , was chosen for analysis.

The point of contact of the beam with the collimator was along boundary No. 4 . A fine mesh was chosen in this area in order to obtain a high resolution of stresses near the beam. Boundary No. 2 was chosen to be far enough away from the beam that conditions along the boundary were not affected by the beam during several bean pulses. Boundaries Nos. 1 and 3 correspond to the inner and outcr rims of the cullimator. Boundary No. 5 was introduced in order to achicve a fine mesh in the vicinity of the beam. The nodal poirt spacing along houndaries ios. 2, 4, and 5 were equally spaced, while the

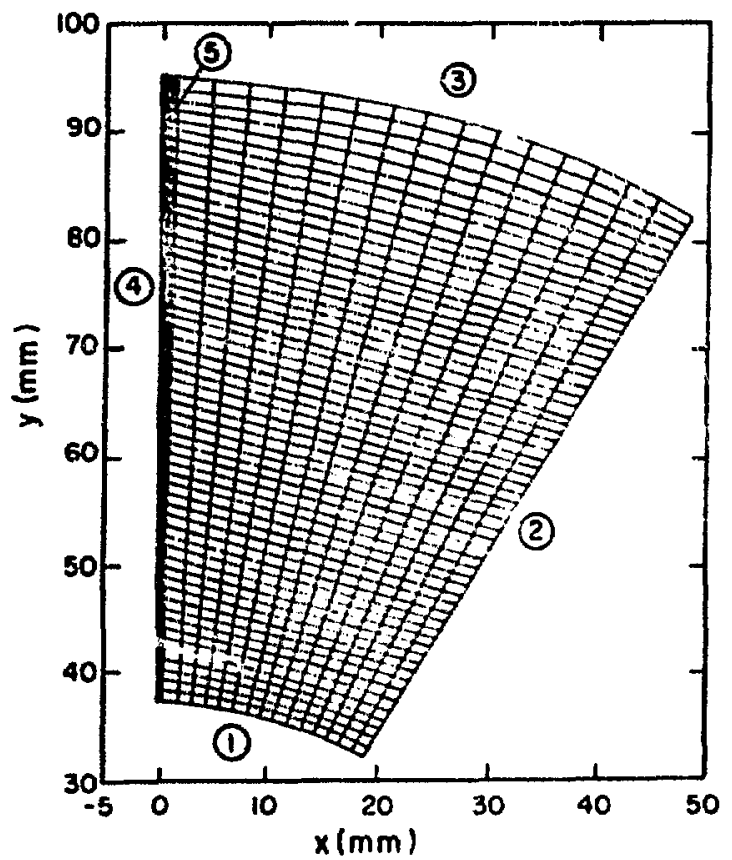

fig. 5. Haterial boundaries i. I nodal point mesh. nodal points along boundaries Nos. 1 and 3 were allowed to be unequaliy spaced. The boundaries in i j nodal point space are shown in Fig. 6 .

\section{B. Initial and Doundary Conditions}

The temperature of the collimator before being contacted by the beam was assumed a unitorm $310.9 \mathrm{~K}$ for purposes of determination of properties. Boundary No. 4 was treated as a zero heat flux boundary because of the symmetry condition. Boundary No. 2 was positioned far enough from the beam that it would not affect the solution and was also specified as having zero heat flux. The collimator is surrounded by a stainiess steel cooling jacket; therefore, ioundary No. 3 was specified to be a constant temperature of $310.9 \mathrm{~K}$.

Boundary No. 1 is actually described by a radiative condition because a vacium exists inside the collimator. TSAAS, however, is not capable of handling a radiative boundary condition. For the analysis of one pulse, the actual boundary condition specified was not expected to affect the results to any great extent, since the heat transferred from the surface would not be very great. For longer times, however, the heat radiated from the boundary would be greater, although it was expected to be less than that conducted away through the collimator. The condition at boundary No. 1 was specified as zero heat flux because this is a much better

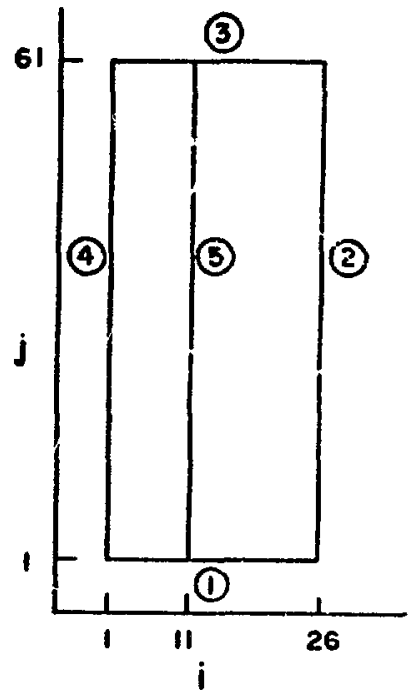

Fig. C. Material boundaries in $i, j$ nodal point space. 
approximation to the radiative conition than is a condition of constant temperature.

The collinator was free to expand in the axial direction, so plane stress conditions were assuned. Stress and displacement along the collimator boundaries were unspocified other than zero displacenent along boundary No. 2 . The boundary conditions are shown in. Fig. 7 .

\section{Analysis of First Pulse at 1-mA Beam Current}

The primary problem of interest was to determine whetller or not the collinator would fail during the first beam pulse at 1-a beam current. If the collimator did not fail during the first pulse, then the temperature and stresses would decrease until the next pulse arrived. Thus 8 ms of tine would be assured in which action could br taken to prevent damage to the collimator. Therefore, attention was focused on the state of the collinator during the first pulse.

1. Uniform Deposition Bean. TSAAS is not capable of treating a continuously variable rate of internal heat generation. Therefore, the Gausaian distribution of heat deprosjtion was first approximated by a nearly rectangular area of constant heat

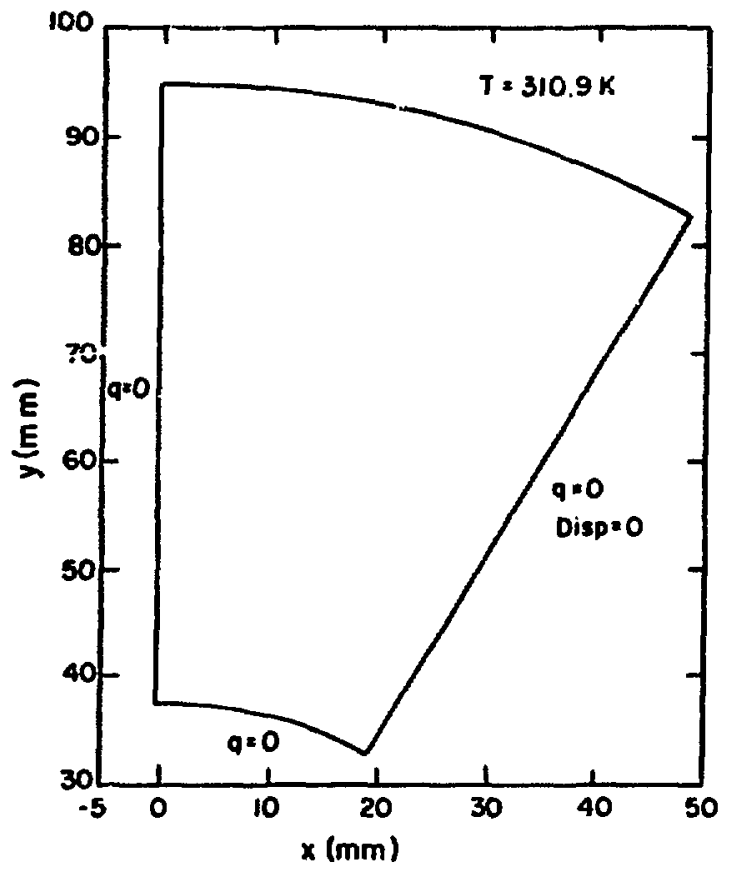

Fig. 7. Boundary conditions applied to collimator segment. generation. The postulated worst case that was analyzed in section II was sodeled. That is, a been area measuring 1 m 10 with anifor rate of heat deposition of $225 \mathrm{~kW} / \mathrm{g}$ was programed f-ito TSMS, using the nodal point wesh and boundary conditions previously described.

Initial calculations were dirested toward determining the bean location on the collientor which produced the earliest failure. A bea located adjacent to the outer rim resulted in the lowest tenperatures and stresses because the constant terperature boundary condition on the outer rin resulted in high rates of heat removal from th- colliantor. When the bean was located adjacent to the inner rim. the stresses were slightly higher than when the bea was in the center of the aterial. Therefore, in the reaninder of the nunerical solutions the bean was located adjacent to the Inner ria. The location and orientation of the bean is shown in Fig. 8 .

Since boundary No. A ts a line of symetry, the codel bean width in the tangential direction is ane-half of that being rodeled. In order to conform to the nodal point esesh. it was necessary to specify the beam to be 7 eleants wide $\times 10$ elements high

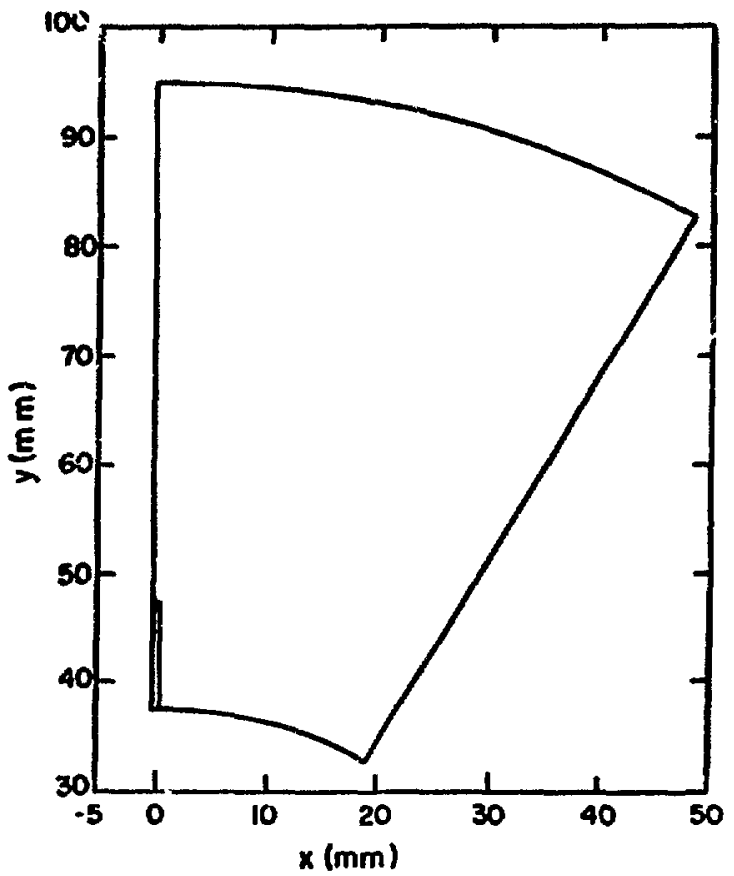

Fig. 8. location and orientation of uniform deposition bean. 
when the bean was adjacent to the inner rim. This gave a sodel bean which was approximately rectangulat in shape, $0.5263 \times 9.921$ This configuration modeled a bean of aspect ratio 9.425 with an area of $10.44 \mathrm{~mm}^{2}$.

The effect of beal aspect ratio on the stresses developed within the bear area was investigated. As indicated by the andlytical results, the stresses were found to be slightly higher for higher aspect ratios. So that the worst probable case could be considered, the highest expected aspect ratio of 10 was used in subsequent studies.

The effect of plastic-eo-elastic modulus ratin on the stresses was investigated by considering raties of 0.005 and 0.013 . The seresses differed by less than 15: therefore, a plastic-to-elastic modulus rat io of 0.005 was used in subsequent cal. culations.

The effect of the thermal boundary condition on the inner ria was investigated by running cases for which the inner rim was insulated, or aleerna* tively constant temperature. is expected, the $t \mathrm{~cm}$ pesatures and stresses were litele changed because of the short time involved in the analysis.

Qrisules obtained from this model are shown in Figs 9 through 11. Tensile, compressive, and shear stresses are ploted as a function of discance from the vertical line of symetry. going out through tho beas a rea after 500 ws of heating. The results agree qualieatively with the analyticial resules. The tenstie stress attains a maximum at the edge of the beam and decreases ipproximately as $\frac{1}{2}$ outside of the bean area. The compressive stress also reaches a maximu at the edge of the bean and is highet than the censtle stress insialc the beam arca.

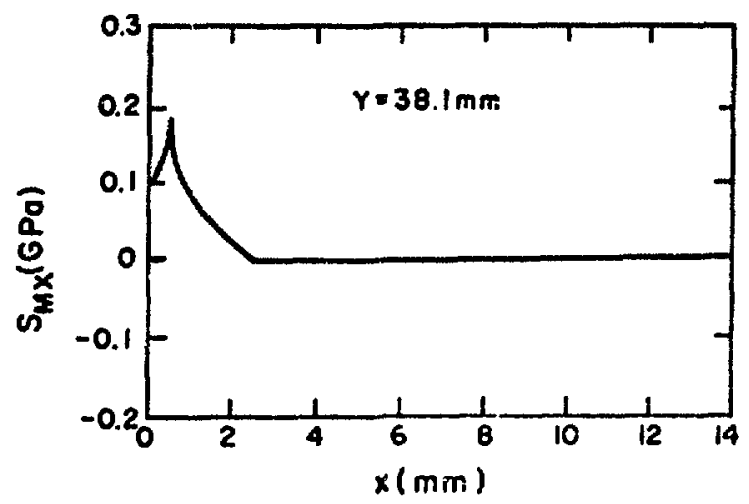

Fig. 9. Maximum normal stress as a function of distance.

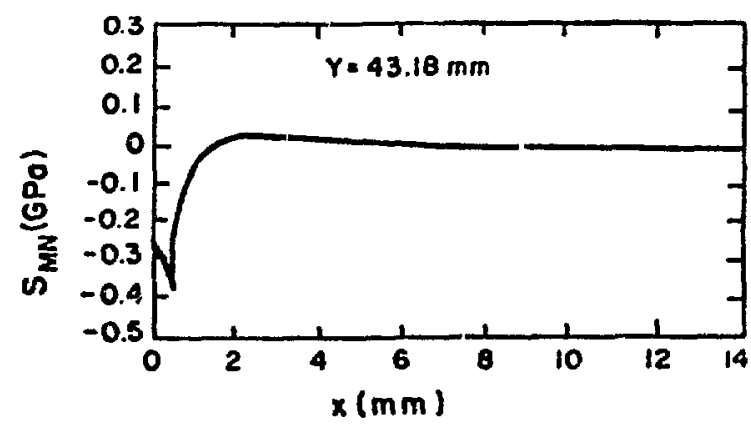

Fig. 10. Minimu normal seress as il function of distance.

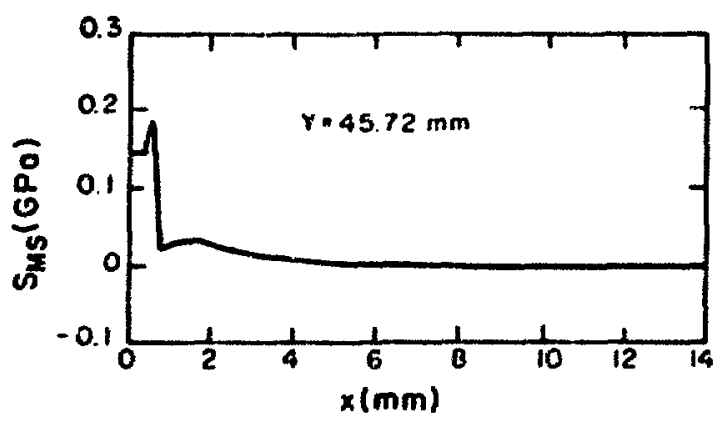

Hip. It. Haximum shear stross as a function of distince.

The shear stress also attains a mairug at the beas edge.

The paximan ecoperature in the heam arew as a function of eitue is shown in fig. 12. The analytial solution is also show, for comparison. It can be seen that the temperatire-pine relationship depures very lietle from linearity and is very similar to the results obtained fron the analytical solution. Part of the nonlinearity is due to the variable properties which were incorporated inte the code, but were not accounted for in the analytical solution. The resules show that very litele heat is conducted away from the beam area durint: the first pulse.

The maximum compressive seress within the heam area is plottod as a function of tine in Fig. 13 . The compressite stress was thosen for analysis because it was higher than the maximutensile stress, as indicated by the analytical solution and Figs. 9 and 10. In addition, the yield stress in compression is the same as that in ecnsion for this tungsten alloy. 


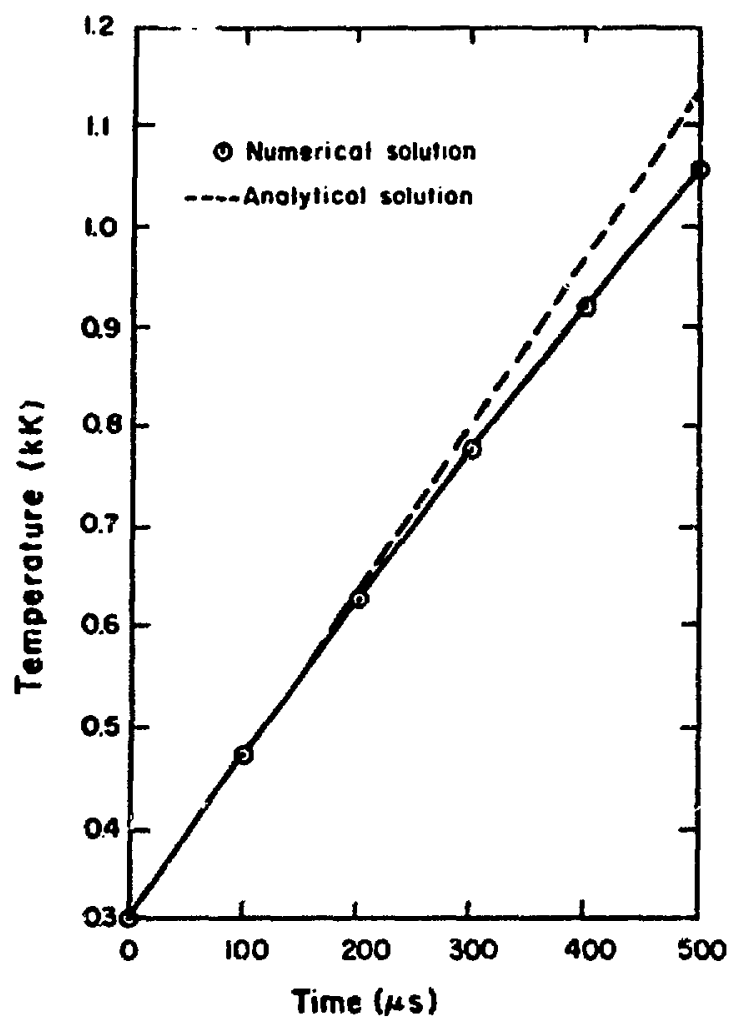

Fig. 12. Maxidus temperature in beas area fur unifor: deposition bean at 1-ah bean current.

Superimpised on the stress curve are plots of the yicld stress ind ultiente tensile stress of the colliantor. The yleld and ultinate stress curves were obtained by plotting the stress corresponding to the ximun teaperature ot each time incrnaent. Temperatures were obtained from Fig. 12, and yield and tensile stresses were obtained from Fig. A-1 in the Appendix.

This manner of interpreting the data is conservative in that the maximum compressive stress does not correspond to the point of maxirum temperature. To be precisely accurate, the compressive, yield, and ultimte stresses at a variety of points within the beas would have to be considered. In this manner, the point where the failure first occurs could be deterained. This procedure would result in a somewhat longer tias to failure. The worst condition would generally correspond to the point of maximum temperature becausc the yield and ultimate stresses decrease significantly with increasing temperature (see Fig. A-1 in the Appendix), while the compressive

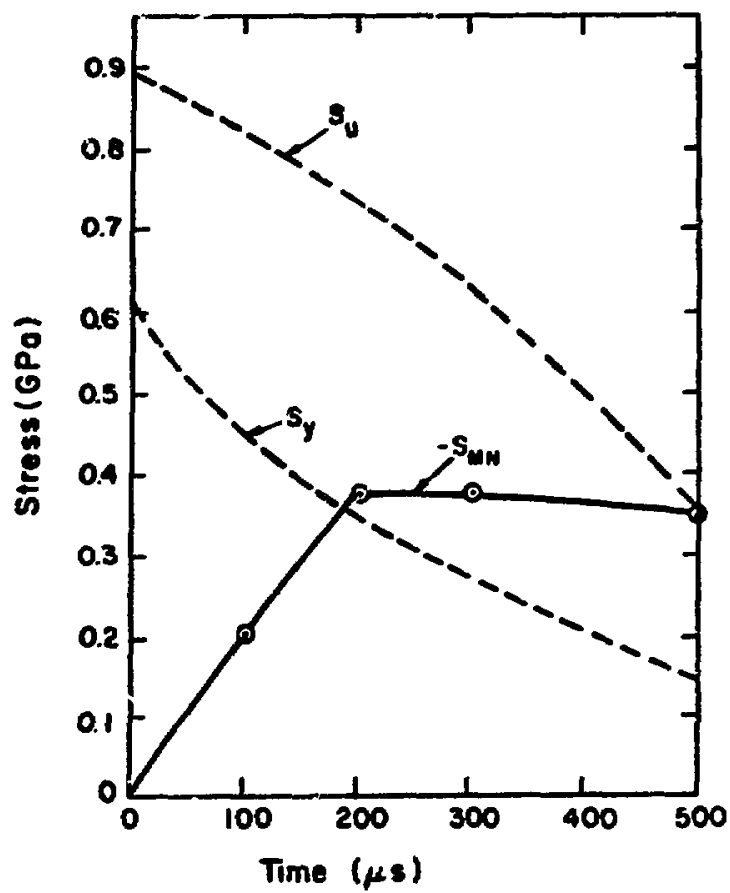

Fag. 13. Maxima compessive seress in bean area for uniform deposition beam at 1-a average bean current.

stress decreases relatively little in going from the point of aximu stress to that of meximur temperature inside the bean ares.

Figure 13 shows that the yield stress is reached after 18, us. After this paint, the stress increases slightly and then relaxes significantly. This is due largely to the fact that the yield stress decreases rapidly with increasing temperature and the stress resulting from similar strains is correspondingly reduced. The ultimate strength of the acerial is just reached after 500 us.

2. Composite Bean. inalyses were made with a biareal beam to achieve a better approxination to the Gaussian distribution of heat deposition. The beam was divided into an inner section with a uniform rate of heat generation equal to the peak of the Gaussian power deposition and an outer section in which the rate of heat generation was also uniform and one-half of that in the inner section. Thus, the same power would be deposited in the collimator, but the deposition would occur over a larger area. With this configuration, it was expected that the outer section would allow greater expansion of the 
material surrounding the inner section and would thus decrease the stresses in the beas area.

Substitution of Eq. (1) into Eq. (2) yields an expression for the power density of he beam.

$\tilde{q}=\frac{\frac{d y}{d z} !}{2 \pi \sigma_{y}^{\sigma_{y}}} e^{-\frac{1}{2}\left[\left(\frac{x^{-}}{\sigma_{x}}\right)^{2}+\left(\frac{y^{-}}{\sigma_{y}}\right)^{2}\right]}$.

In tungsten, $\frac{d w}{d z}$ is approximately $13.5 \frac{\mathrm{GeV}}{\mathrm{g} \cdot \mathrm{m}^{2}}$ for 600-MeV protons. For the bean with aspect ratio 10 , $\sigma_{x}=0.43 \mathrm{mand} \sigma_{y}=4.3 \mathrm{~mm}$. Thus, for an average current of $1 \mathrm{~mA}$, Eq. (11) ylelds a Gausslan power deposition distribution where the peak power deposition is

$\dot{q}_{0}=\frac{\frac{d w}{d z} I}{2 \pi \sigma_{x} \sigma_{y}}$

or $193.7 \frac{\mathrm{kw}}{8}$.

The total power deposited in the collimator is proportional to $\bar{Q}$, where

$\bar{Q}=\iint_{\infty}^{\infty} \dot{q} d x^{-} d y^{-}$.

Substitution of Eq. (11) into Eq. (13) and cvaluation of the integral gives the result

$\dot{Q}=\frac{d W}{d z} I$.

For the case being considered, the rate of energy deposition is directly proportiona: to $2.25 \frac{\mathrm{m} \cdot \mathrm{N} \cdot \mathrm{m} \mathrm{m}^{2}}{\mathrm{~g}}$. Elimination of $\frac{d w}{d z}$ from Eqs. (12) and (14) yields

$\tilde{Q}=2 \pi \sigma_{x} \sigma_{y} \dot{q}_{a}$.

Equating the sum of the heat generation in the two areas to that generated by the Gaussian bean,

$A_{1} \dot{q}_{0}+A_{2} \frac{\bar{q}_{0}}{2}=2 \pi \sigma_{x} \sigma_{y} \dot{q}_{0}$.
The areas of the two sections are given by

$A_{1}=e_{x_{1}}{ }^{2} y_{1} \cdot$

$A_{2}=2 x_{2}{ }^{2} y_{2}-x_{1} x^{2} y_{1}$.

For a beam of aspect ratio 10 and an outer section having dimensions twice that of the inner section

${ }^{R} y_{1}=10^{2} x_{1}$.

$\varepsilon_{2}=10 x_{2} \cdot$

$i_{y_{2}}=2 x_{y_{1}}$.

$x_{2}=2 z_{1} \cdot$

Substitution of Eqs. (19) into E.ps. (17) and (18). which are then substituted into Eq. (16), yiclds

$R_{x_{1}}=\frac{\sqrt{-\pi \sigma_{x}^{0} y}}{5}$.

From Eqs. (19) and (20) the desired dimensions of the areas were found to be

$x_{1}=0.6817 \mathrm{~mm}$.

$2_{1}=6.817 \mathrm{~mm}$.

$l_{x_{2}}=1.363 \mathrm{~mm}$,

$a_{2}=13.63 \mathrm{~mm}$.

The power deposition and the resulting approximation to it for the $y$-direction are shown in Fig. 14 .

Sisce boundary No. 4 is a 1 ine of symetry, the ideal model bean width in the tangential direction is onehalf that indicated for $k_{x_{1}}$ and $k_{x_{2}}$ in Eqs. (21). 


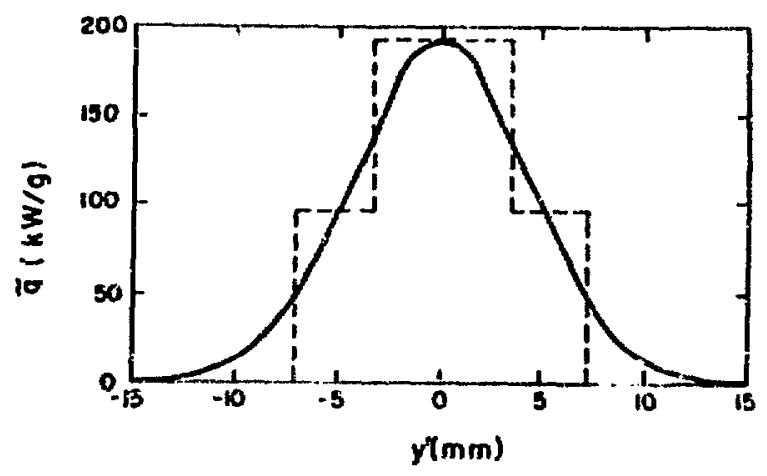

Fir. 14. Distritution of bead power deposition in $y$-direction and two-sectioned approx $j$." motion.

To conform to the nodal point wesh used in the code, the inner area was 4 elewents wife $x 7$ elcments high and the ourer area was $g$ elements wide x 14 elements high. This produced approximately rectangular areas with simensions of 0.3109 ma $x$ 6.947 for the inner section and 0.7076 . $x$ 13.89 mat for the outer scction, and corresponding aspect ratios of 11.17 and 9.815. Thus, the porer deposited in the composite, model was $2.322 \frac{1}{8}$ as compared to $2.350 \frac{\mathrm{M} \text { - }}{\mathrm{k}} \mathrm{C}^{2}$ in the uniform deposi tion model. The orientation and incation of the composite beam is shown in Fig. It.

The maximin temperatures at ained in each of the bean sections are shown as functions of time in Fig. 16. The temperature increase in hath sections is very nearly linear, but the sloje pf both of the curves is less than that for the unifo:th deposition model. This is caused by the fict that a lower rate of energy deposition was applied over a larger area in the composite morlel.

The maximum compressive stress within the inner section of the beam is plotted as a function of time in Fig. 17. Also shown are the yield and witimate stresses of the collimasur correspotaling to the maximum tenperature attained within the imer hean section at each time. The yintd stress is reached af ter 200 us at $1-m \lambda$ beam current. This is a slightly longer time to yicld than the uniform deposition altalysis produced. The stress continues to increase after yielding unt il it reaches a maximum al 250 is where te falls off rapidlv, never approiching the

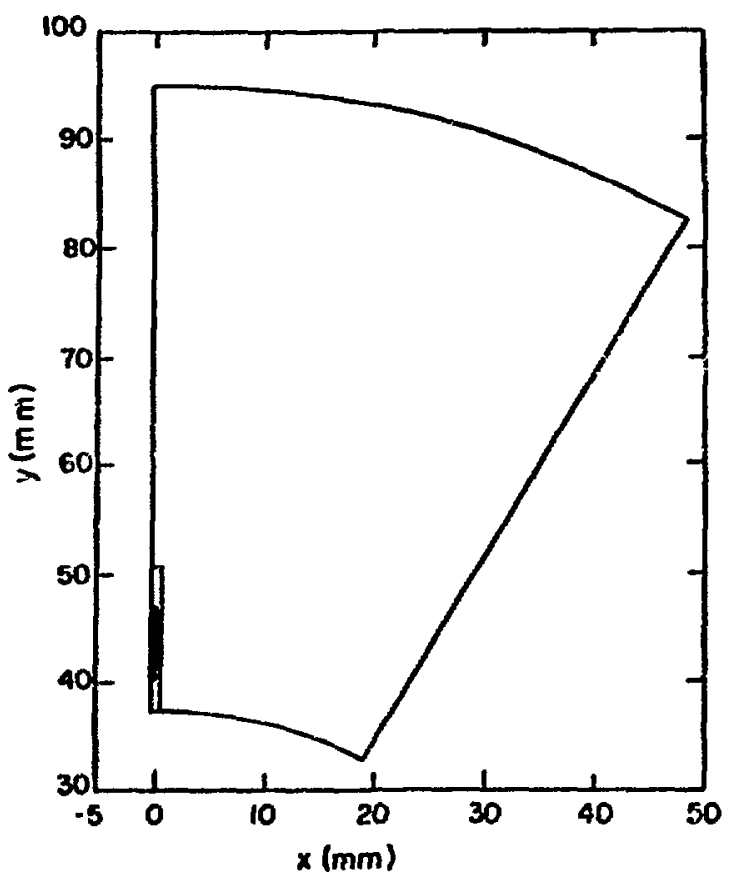

Fig. 15. Gcometry and Incation of composite bean.

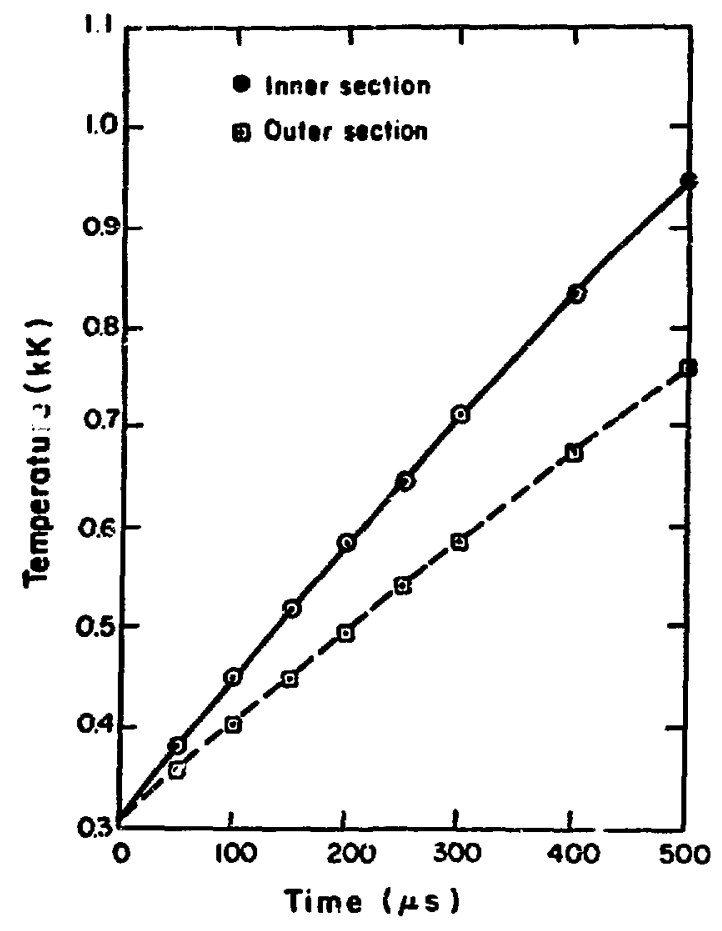

Fig. 16. Maximum temperature in beam area of compositc beam. 


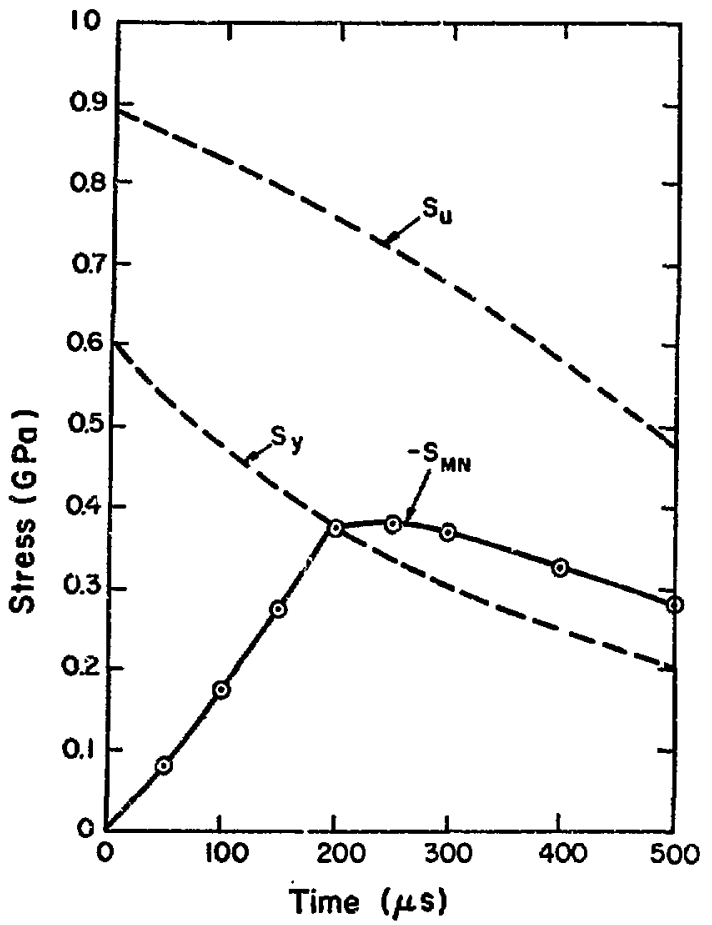

Fig. 17. Maximum compressive stress in inner section of composite beam.

ultimate stress during the first bean pulse. The more rapid decrease of stress after reaching the yield stress as compared to the uniform deposition model can be attributed to increased expansion of the material surrounding the inner section.

The maximum compressive stress within the outer section of the beain is shown in Fig. 18, along with the yield and ultimate stresses corresponding to the maximum temperature attained within the outer section at each timc. It can be seen that the stress increases more slowly than in the inner section and reaches the yield stress after $295 \mu \mathrm{s}$. After this time, the stress continues to increase to a level slightly higher than that reached in the inner section. However, the temperature is lower in the outer section. Therefore, the ultimate stress remains much higher than the compression stress.

\section{Analysis of $0.1 \mathrm{~mA}$ Pulses}

Another problem of $i_{1}$ : erest is the condition of the collimator under lower levels of beam current, $0.1 \mathrm{~mA}$, for times up to $1 \mathrm{~s}$. Under these

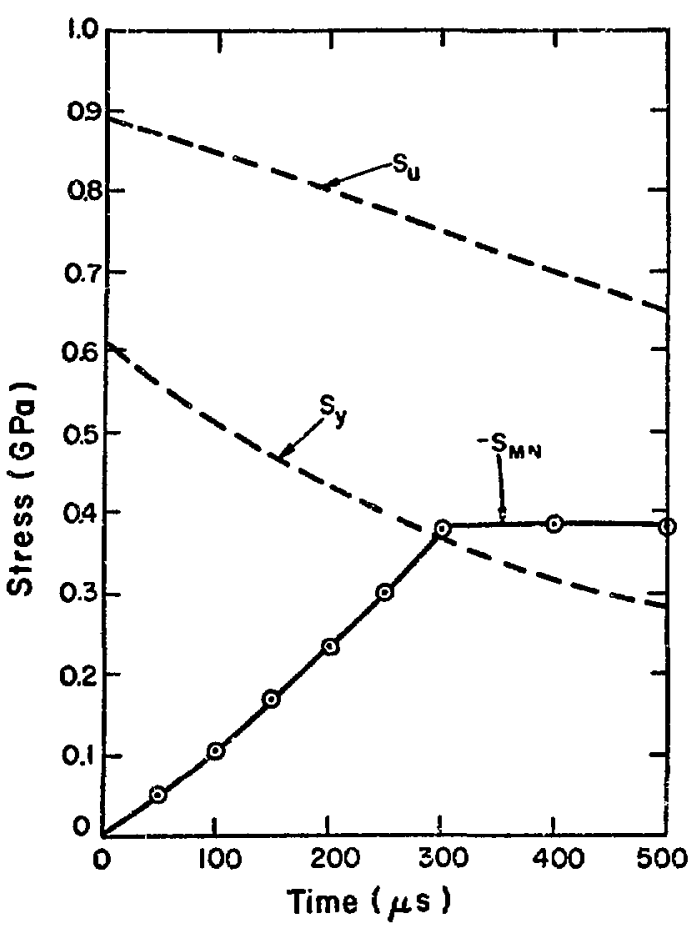

Fig. 18, Maximum compressive stress in outer section of composite beam.

conditions the stresses developed in the collimator at a given time would be expected to be much lower because the power deposition is one-tenth of that for the previous case. In addition, since the collimator would be expected to survive far beyond one beam pulse, conduction of thermal energy away from the beam would become significant. Conduction would thus reduce the stresses in the vicinity of the beam.

Since the length of one pulse would be an insignificant time interval compared to the expected time to failure, a quasi-steady-state assumption was made. In this treatment the beam was assumed tc be continuous rather than of a pulsatile nature. The power deposition for the continuous bean was taken to be $6 \%$ of that from the pulsatile beam so that the same amount of energy wosld be deposited over the pulse period.

The calculations were based on data which indicated a peak instantaneous power deposition of $225 \frac{\mathrm{kW}}{\mathrm{g}}$ over an effective area of $10 \mathrm{~mm}^{2}$ at $1-\mathrm{mA}$ 
average beam current. 2 Thus, the power deposition for the $0.1-\mathrm{mA}$ beam was $1.35 \frac{\mathrm{kW}}{\mathrm{g}}$.

The beam was located adjacent to the inner rim and had uniform power deposition. However, in this case the beam had an aspect ratio of 2 , For an aspect ratio of 2 ,

$R_{y}=2 R_{x}$

and

$A=2 e_{x}^{2}$

From Fqs. (22) and (23) one obtains

$\ell_{x}=2.236 \mathrm{~mm}$,

$l_{y}=4.472 \mathrm{~mm}$

Since boundary No. $A$ is a line of symmetry, the ideal model beam width in the tangential direction is one-half of that indicated in Eq. (24). In order to conform to the nodal point mesh, the beam was 8 ejements wide $\times 5$ elements high. This produced a model beam approximately rectangular in shape, $1.133 \mathrm{~mm} \times 4.950 \mathrm{~mm}$, which modeled a beam or: aspect ratio 2,184 .

The maximum temperature within the bean area as a function of time is shown in Fig. 19. The collimator reaches a much higher temperature than in the previous case because of the longer heating time. The temperature reaches $1.366 \mathrm{kK}$, which is the maximum serviceable temperature of the tungsten alloy, after $0.57 \mathrm{~s}$.

The maximum compressive stress developed inside the beam area is shown in Fig. 20 and the stresses developed outside of the bean are shown in Fig. 21. The stress nutside the beam area reaches a higher value, but, due tr the lower cemperature, the yield and ultimate stresses are exceecied at slightly later times than inside the beam area. The yield stress is exceeded after $0.23 \mathrm{~s}$ and the ultimate stress is exceeded after $0.48 \mathrm{~s}$.

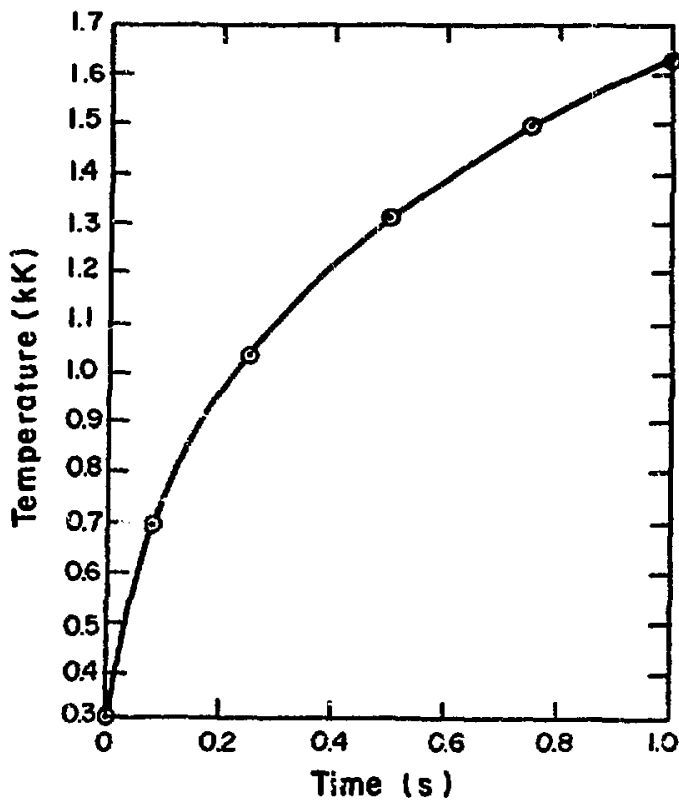

Fig. 19. Maximum temperature in beam area for 0.1 average beam current.

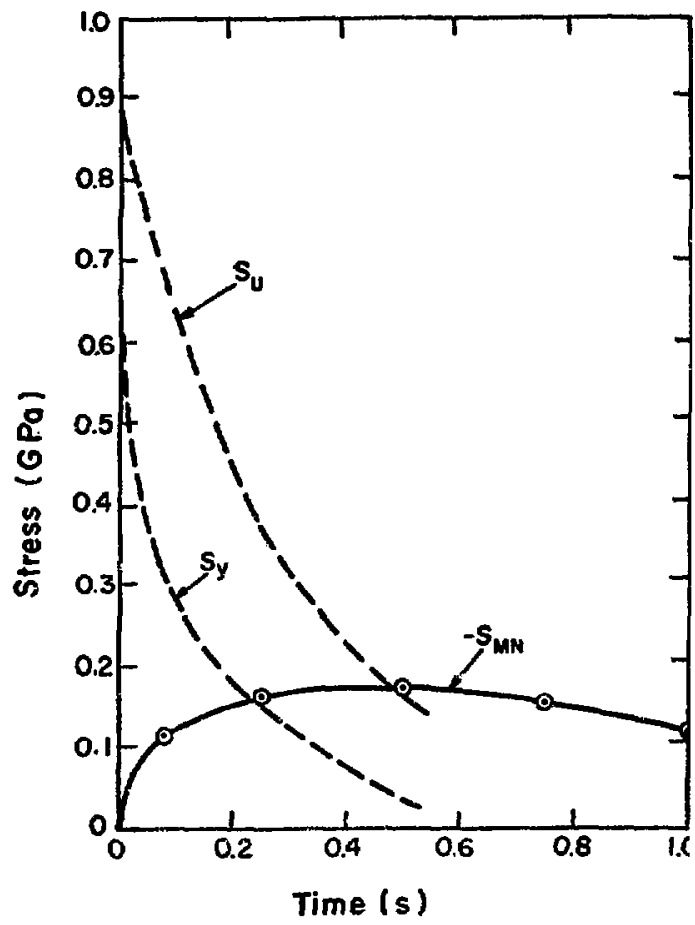

Fig. 20. Maximum compressive stresi inside bean at $0.1 \mathrm{~mA}$ average beam current. 


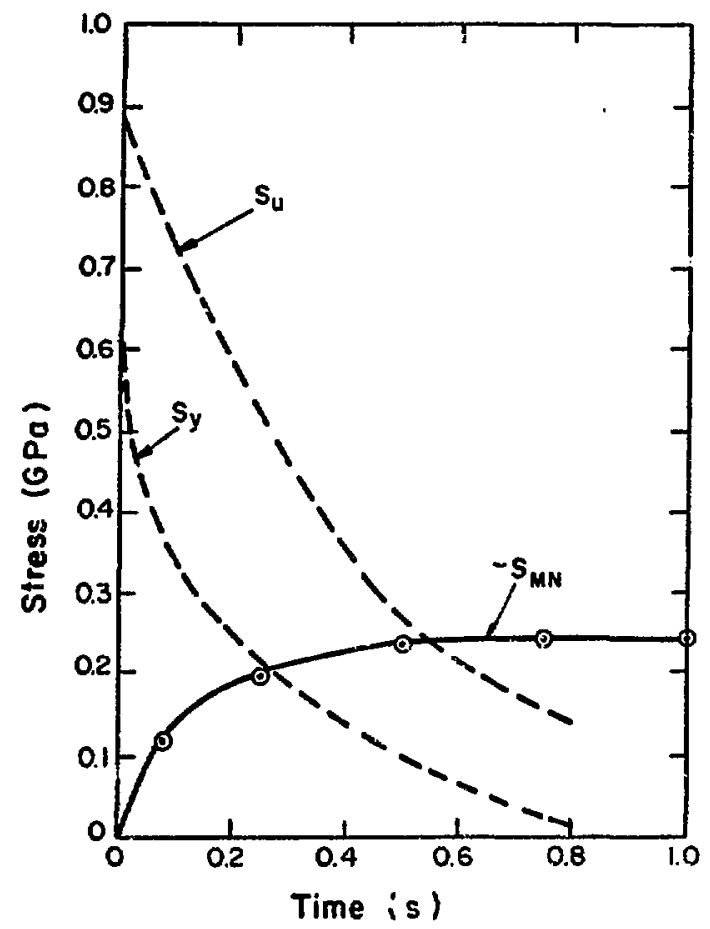

Fig. 21. Maximum compressive stress outside bean at $0.1 \mathrm{~mA}$ average beam current.

\section{THERMAL SHOCK ESTTMATES}

Pulse heating can caure the temperature of the materfal to rise faster than its ability to respond by thermal expansion, giving rise to dynamfe stresses. This subject has been Investigated for pulse neutron heating of reactu: fuel elements 4,5 and aerodynamic heating. 6 Generally, it was found that theoretical calculations overestimate deflection and stress compared with experiments in both elastic and elastic-plastic formulation, but the calculated vs observed vibrational frequency was reasonably close.

Considering the collimator first as a cylindrical shell, the period of natural vibration is found to be

$T_{p}=\frac{R_{m}}{\sqrt{E / \rho}}=1.45 \times 10^{-5} \mathrm{~s}$.

Burgreen and others found that for ratios of heating time to natural period greater than 3 , the expansion follows the temperature rise and there is no dynamic effect. For the collimator, the ratio is $500 \times 10^{-6} / 1.45 \times 10^{-5}$, or $T_{h} / T_{p}=34.5$.
As a check, the wave propegation time is $\left(R_{0}-R_{i}\right) / C=\tau$, and $\tau=1.36 \times 10^{-5} \mathrm{~s}$. The ratio of heating time to wave propagation time is 36.8 .

For longitudinal waves, the expression for naturdl period becomes $T_{p}=2 \ell / C=1.75 \times 10^{-5} \mathrm{~s}$. The ratio in this case is 28.6 .

Considering the collimator to be a plate of length $2 \pi \mathrm{R}_{\mathrm{m}}$ and width $\Delta R$, Boley finds for a step temperature input on one face that the dynamic effects are negligiblo for values of the nondimensional parameter $B_{1}$ greater than 3.5 .

$B_{1}=r\left(\frac{D}{h \rho}\right)^{1 / 4} / \Delta R \sqrt{K}$

where

$D=\frac{E h^{3}}{12(1-v)}$

$B_{1}$ for the collimator is 51.2 compared to 3.5 which gives less than $10 \%$ error in deflection.

Based on the above values, it is felt that shock amplification of stresses is improbable and that quasi-static solutions such as obtained from TSAAS are adequate.

\section{CONCLUSIONS}

The numerical solutions obtained with the conposite beam model indicate that the yield stress of the tungsten alloy collimator will be reached after 200 us at 1- $\pi A$ average beam current. The ultimate stress, however, will not be reached during one beam pulse. Thus, if permanent deformation of the collimator can be allowed, the results indicate that the collimator will survive one beam pulse.

The numerical results achieved with the uniform deposition beam model indicate the same qualitative results as the composite beam. Yielding occurs slightly earlier at $185 \mu \mathrm{s}$ and the stress in the nlastic range does not decrease quite as much, so that the ultimate stress is just reached at the end of the first pulse.

The biareal model, however, is a better approximation to the bean power deposition. The uniform deposition model deposits a relatively high amount of power over a relatively small area. This 
produces higher temperatures and somewhat higher stress. The higher texperatures lead to reduced yield and ultimate stresses, and, therefore, an earlier time of failure.

The analytical solution yields a good approximation to the temperature and stress that develops during the first beam pulse. Agreement with the numerical results of the uniform deposition model is very good in the elastic range. Relaxation of stress in the plastic range is not predicted by the analytical solution, however. Also, the assumption of zero thermal conductivity produces an overestimate of the temperature by $328 \mathrm{~K}$ at the end of tlie pulse. The temperature overestimate leads to a significantly lower ultimate stress at the end of the pulse.
The terperature and stress predicted by the analytical treatment are directly proportional to bea: power deposition density. If data for an approximation to the Gaussian beas power deposition derived in a manner sinilar to that used in the couposite bear analysis were used in the analytical solution, such as a lower power deposition density over a larger area, the results would be expected $t_{1}$ agree well with the composite analysis in the elastic range.

Results of the numerical analysis of the colli mator at $0.1-\mathrm{mA}$ arerage beam current show that the yield stress is reached after $0.23 \mathrm{~s}$ and the ultimate stress is exceeded after $0.48 \mathrm{~s}$. In addition, the maximp allowable tenperature of the tungsten alloy is attained after $0.57 \mathrm{~s}$.

APPENDIX

THEPMAL AND MECHANICAL FROPERTIES

Thermal and mechanical properties were extrapolated from numerous references for tungsten and tungsten alloys. $7,8,9$ Yield and ultimate tensile stresses for $95 \mathrm{w}-3,5 \mathrm{Ni}-1.5 \mathrm{Fe}$ from room temperature to $1.366 \mathrm{kK}$ are show in Fig. A-1. The maximum allowable temperature of the alloy is regarded to lie $1.366 \mathrm{kK}$. The dashed portions of the curves ind cate extrapolated or interpolated values.

The modulus of elasticity is shown in Fig. A-2. The modulus was extrapolated at constant slope from known data. Figures $A-3$ through $A-5$ show the coefficient of thermal expansion, thermal conductivity, and specific heat. The specific heat was extrapolated at the same slope as tungsten from a known value for the alloy at roon temperature. Variable properties were incorporated into TSAAS by inputting data at $0.2932,0.5332,0.8109,1.089$, and $1.366 \mathrm{kK}$.

The effective plastic-to-elastic modulus ratio for calculations in the plastic range was obtained from data at room temperature. The plastic modulus was determined by assuming a linear stress-strain relation between the yield stress at $0.2 \%$ offset to the ultimate tensile stress at 158 elongation in $50.8 \mathrm{~mm}$ as shown in Fig. A-6. The ratio of plasticto-elastic moduli was thus found to be 0.005031 . This ratio was held constant with temperature.

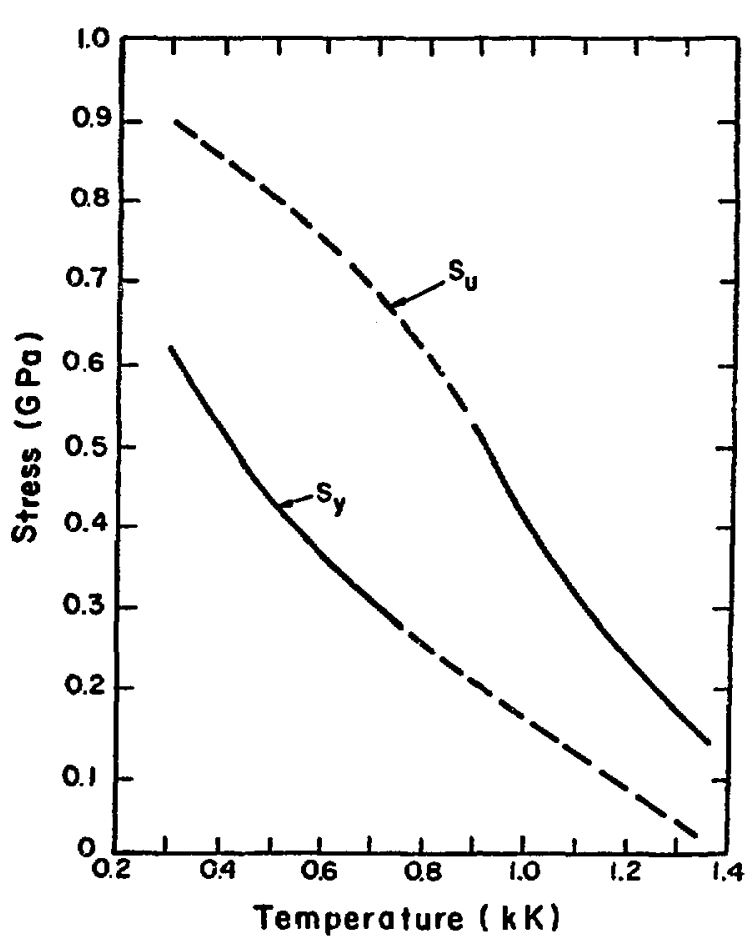

Fig. A-1. Yield and ultimate tensile stresses of $95 \mathrm{~W}-3.5 \mathrm{Ni}-1.5 \mathrm{Fe}$. 


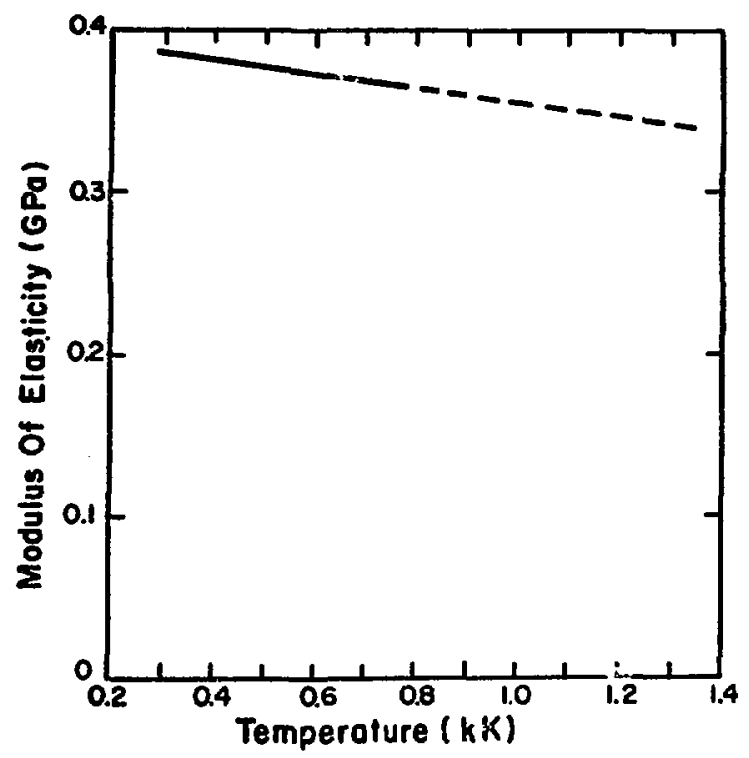

Fig. A-2. Hodulus of elasticity of $95 \mathrm{~W}-3.5 \mathrm{Ni}-$ $1.5 \mathrm{Fe}$.

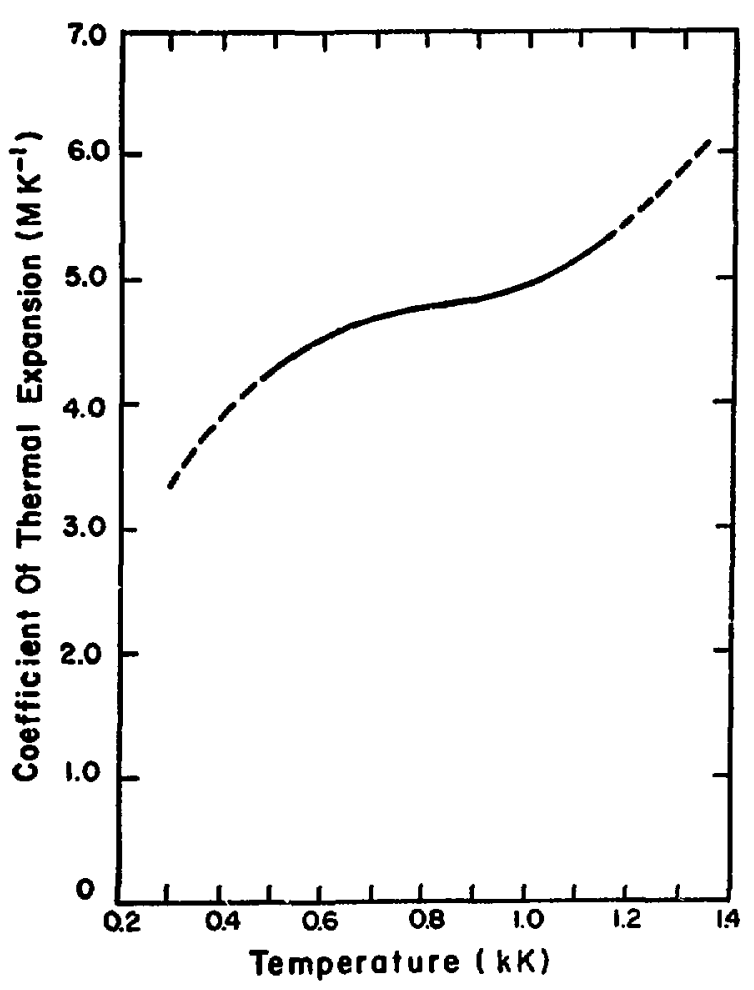

Fig. A-3. Coefficient of thermal expansion of $95 \mathrm{~W}-3.5 \mathrm{Ni}-1.5 \mathrm{Fe}$.

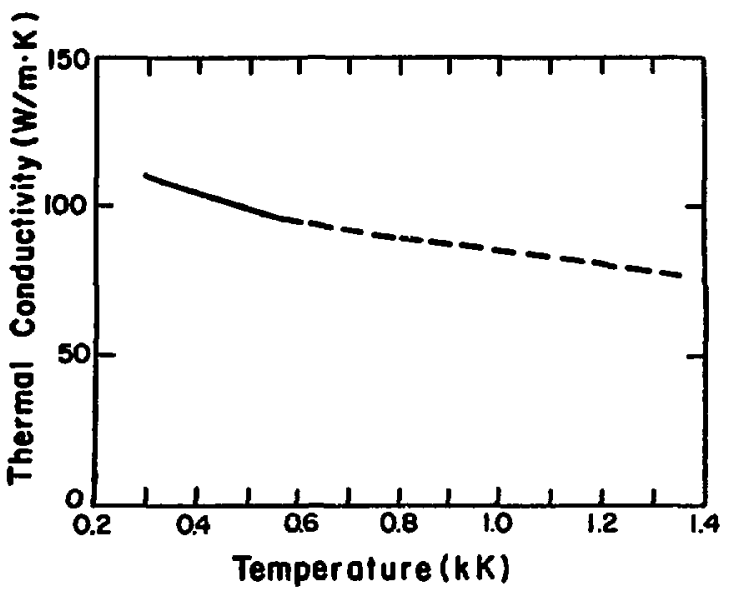

Fig. A-4. Thermal conductivity of $95 \mathrm{~W}-3.5 \mathrm{Ni}-$ $1.5 \mathrm{~F}=$

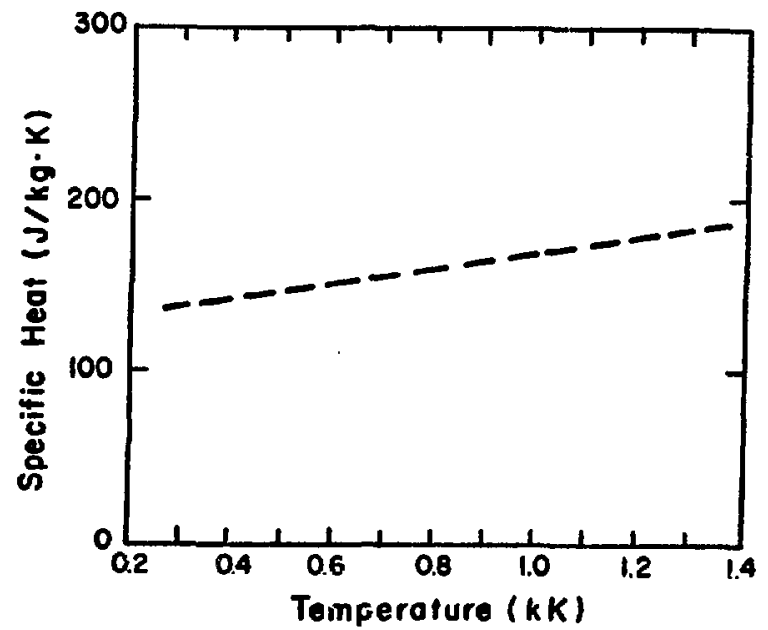

Fig. A-5. Specific heat of $95 \mathrm{~W}-3.5 \mathrm{Ni}-1.5 \mathrm{Fe}$.

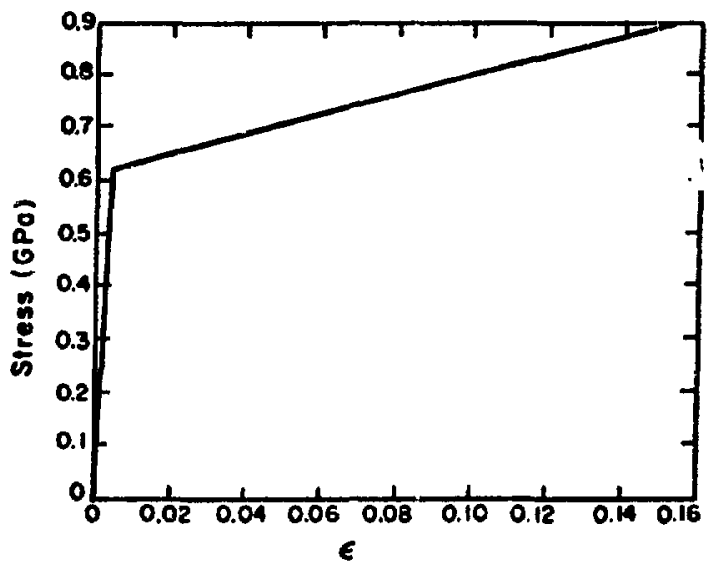

Fig. A-6. Determination of effective plastic-toelastic modulus ratio. 


\section{ACKNOWLEUGMENTS}

The authors wish to express their appreciation to R. V. Browning, WX-3, and C. A. Ariderson, R-4, for their helpful explanations of the intricacies of TSAAS.

\section{REFERENCES}

1. R. J. Roark, Formulas for Stress and Strain (McGraw-Hil1, 1965).

2. R. J. Macek, personal communication, May 1975.

3. R. V. Browning, D. G. Miller, and C. A. Anderson, "TSAAS: Finite Element Thermal and Stress Analysis of Axisymetric Solids with Orthotropic Temperature-Depencient Material Properties," Los Alamos Scientific Laboratory report LA-5599-AS (May 1974).

4. J. A. Reuscher, "Analysis of Internal Heating Shock Effects in Reactor Fuel Components," Nuclear Engineering Design 18, 213-251 (1972).

5. D. Burgreen, "Thermoelastic Dynamics of Rods, Thin Shell, and Solid Spheres," Nuclear Science and Engineering 12, 203-217 (1962).

6. B. A. Boley and J, H. Weiner. Theory of Thermal Stress (John Wiley and Sons, 1960).

7. Materials Properties Data Book, Report 2275, Hevision of November 17, 1970, Contract SNP-1, Aerojet Nuclear Systems Company, Division of Aerojet-General.

8. F. C. llolt 2 anil R.J. Van Thyne, "Development anc Evaluation of High-Tenperature Tungsten Alloys, Sumary Report." Al:C Research and Deve opment report, Contract AT(33-3)-4 Task 1, November 12, $19: 99$.

9. High Density Metals, Mallory Metallurgical Company. Form 6-278 54 12-6h. ip. 4-5.

\section{NOMENCLATUAE}

a Seni-major axis of cllipke.

A Area of bean in mollel.

b Semi-minor axis of eltipse.

c speed of sound.

$c_{p}$ Specific heat at conseane prossire.

l: volutus of elasticity.

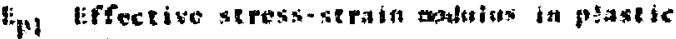
mane.

It Thichness of plites.

1. 5 Nodal point indices.

- Alerafe hea ctirfont.

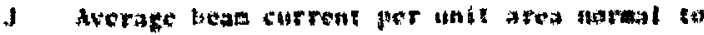
bean.

h Themal conducititity.
$K$ Theral diffusivity.

2 Length of bean ares.

9 Heat transfer rate per unit area.

$\dot{q}$ Beall power deposition per unit mass.

$\ddot{q}_{0}$ Maximun bean power deposition per unit mass.

$Q$ Total beas enexgy deposited in collimator.

$r$ Radial distance from center of disc.

$R_{i}$ Inside radius of collientor.

$R_{m}$ Mean radius of cylinder.

$R_{0}$ Outside radius of collimetor.

SWN Hinitu noral stress.

SMS Maximu shear stress.

$S_{\text {MX Maxinum normal stress. }}$

$S_{y}$ Radial seress.

$S_{t}$ Tangential stress.

$S_{u}$ Ultimate stress.

Sy Yield stress.

$t$ Tiwe fros beginning of bean pulse.

ty Time at whith yield stress is reached.

$T$ Temeruture.

$T_{p}$ Period of netural vibration.

$T_{h}$ Heating tine.

$v$ Volune.

w Kinetic energy of proton.

$x$ Cartesian coordinate normal to bean in direction of narrowest beu dimension, with origin at centerline of collimator.

y Cartesian coordinate nomal to beal in direction of largest bean dimension, with origin at centerline of collimator.

2 Cartesian coordinate in direction of proton bean.

a Coefficient of thermal expansion.

c Material strain.

* Poisson's ratio.

- Material density.

- Standard deviation of Gaussian distribution.

7 wave propagstion time.

Subseriprs:

$x, y$ Component of the sybol in the $x$ and $y$ di rections, respectively.

1 notores the inner section of a twonsection approxisation to the Gaussian curve.

2 Denotes the outer section of a two-section approximution to the caussian curve.

Superseripe:

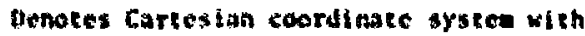
orlitia at center of proton beat. 